\title{
A REAL TIME EMULATOR OF VARIABLE PITCH WIND TURBINES USING TORQUE-CONTROLLED INDUCTION MOTORS
}

\author{
Tamer A. kawady, MIEEE and Naema Mansour \\ Electrical Engineering Department, Faculty of Engineering, \\ Minoufiya University, Shebin El-Kom, Egypt
}

\begin{abstract}
Owing to the technical difficulties of experimental investigations of real wind turbines, Wind Turbine Emulator (WTE) plays a role for performing such experimental tasks. This facilitates to conduct advanced research efforts for wind energy conversion system applications without reliance on natural wind resources. In this paper, a WTE (able to emulate the steady-state and dynamic wind turbine behavior) is experimentally developed. This represents a chance to validate not only the behavior of the proposed controllers, but also to extensively evaluate the properness of their developed dynamic models as well. For this aim, a motor generator set based two induction motors and Digital Signal Possessing (DSP) board were used to develop the WTE in order to simulate the aerodynamic characteristics of fixed speed-variable pitch wind turbine. The response of the proposed WTE during wind speed variations and the behavior of its related pitch controller are tested and recorded. All presented test results corroborated the efficacy of the developed WTE for profiling the dynamic behavior of variable pitch turbines for analyzing wind farm applications.

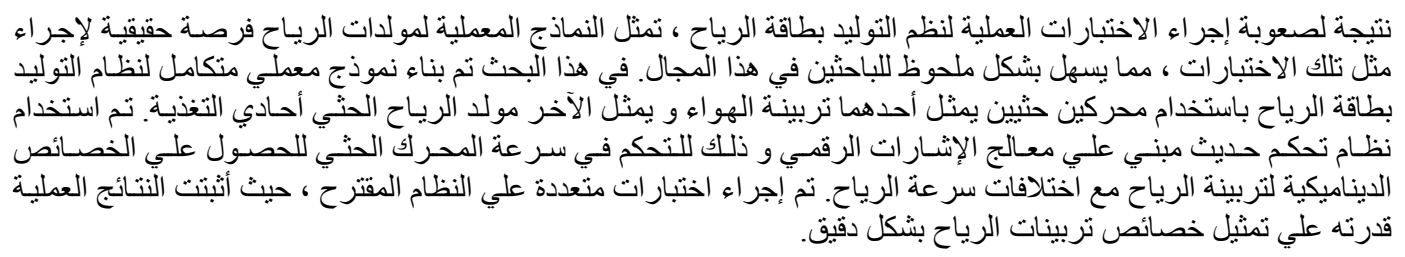

Keywords: Wind Energy, Wind Turbine Emulator (WTE), Digital Signal Processing (DSP) and Variable Pitch Control.

\section{INTRODUCTION}

Recently, wind power is the fastest growing electric power industry in the world. The phenomenal growth of this industry can be attributed to the rapid progress made in wind turbine technology in the recent years. Over the last ten years, technological progress has led to the development of turbines with high power capture efficiency [1]. Modern large wind turbines are supported with sophisticated control systems which are organized to support several modes of operation such as start-up, shut-down, power production .... etc.

As commonly experienced, it is very difficult and sometimes impossible to do experimental studies of control strategy for wind generation systems in the laboratory. This is mainly due to some factors such as its complicated and interactive control strategies, its different features such as the uncontrollable natural characteristic of wind speed, and the large size of wind turbines. Moreover, it is very difficult to manufacture a laboratory wind turbine prototype. As a result, a great deal of research has been focused on the development of new turbine design to reduce the costs of wind power and to make wind turbines more economical and efficient. Toward the development and testing advanced control strategies of wind turbine, the need of a controllable experiment platform without reliance on natural wind resources is very important. So, the wind turbine emulator (WTE) which can emulate the aerodynamic wind turbine behavior is developed. At present, wind turbine simulators have become a necessary tool for research laboratories to enhance the quality of the wind energy conversion system and to enhance the related educational efforts.

Due to the importance of the WTE, different contributions were conducted for emulating the dynamic behavior of wind turbines. These studies mainly focused on emulating the aerodynamic model 
of the wind turbine rotor in order to control the torque output of the equipped motor to simulate the torque-speed curve for an actual wind turbine [2-8]. Once the torque (or the power coefficient curve) of the wind turbine is known, the torque-speed curve can then be determined. Most of these developed emulators were based on utilizing either DC motors [2-5] or induction ones [6-8]. However, these published contributions simulated the performance of fixed pitch turbine in the range variation of wind speed within the rated one considering stall control mechanisms behind the rated wind speed.

In this paper, the affect of pitch angle control on the wind turbine aerodynamic torque behind the rated wind speed is included. Then, fixed speedvariable pitch WTE was experimentally simulated. Then, effects of pitch angle on the aerodynamic characteristics when the wind speed exceeds the rated one are investigated. For this target, a $7.5-\mathrm{kW}$ induction motor was utilized as a prime mover. A digital signal processing (DSP) board is used to interface the wind speed generator and to perform the speed-control action of the utilized inverter for the prime mover. The related tracing and plotting package "via the related host computer" was utilized to record and verify the corresponding currents, voltages and emulated wind speed.

The paper was organized as follows. Benefits and essence of WTE were emphasized in section 2. The description of the mathematical model of wind turbine is outlined in section 3. Utilized "Pitchcontrol" mechanism is outlined in section 4. Hardware details of the developed WTE are extensively explored in section 5. Section 6 highlights the performance of the developed WTE with different testing cases validating the ability of the constructed emulator for performing the variable pitch control action. Finally, paper recommendations and conclusions are summarized in section 7 .

\section{2. $\mathrm{WTE}_{\mathrm{S}}$ SCOPE, BENEFITS AND CONSTRUCTION}

Different benefits can be gained with such WTEs. They can be used for research applications to drive an electrical generator in a similar way as a wind turbine, by reproducing the torque developed by a wind turbine for a given wind velocity. Also, it can be used as an educational tool to teach the behavior, operation and control of wind turbines.

The basic construction of WTEs comprises an electrical motor (induction, DC or permanent magnet motor) that is electrically controlled to simulate the torque-speed curve of actual wind turbines, which they emphasize on how to control the output torque of the motor according to the current wind speed and the rotating speed of the wind turbine. This is typically accomplished with modern power electronic elements such as IGBTs in conjunction with modern micro-controller or DSP board for driving the firing sequence of the utilized IGBTs' gates to perform the aimed speed-control of the utilized electrical motor. Speed and torque control of this electrical motor is acquired based on the aerodynamic model of the wind turbine rotor. Once the torque or power coefficient curve of wind turbine is known, the torque-speed curve can then be determined.

As described in Fig. 1, the WTE is based on the electrical energy conversion system, where the utilized motor is electrically controlled to emulate the own characteristics of wind turbines. A $7.5 \mathrm{~kW}$ squirrel cage induction motor is controlled to reproduce the $12.7 \mathrm{~kW}$ wind turbine torque. Upon the stored $\mathrm{CP}-\lambda$ curve of the selected wind turbine, the selected wind speed, the corresponding developed wind torque and the calculated pitch angle are utilized to perform the control action of the utilized prime-mover. The mathematical model of the wind turbine which implemented based-DSP board is used to calculate the reference signals which will be used as reference for a PI controller to provide the control signal which will be fed to the speed-control inverter.

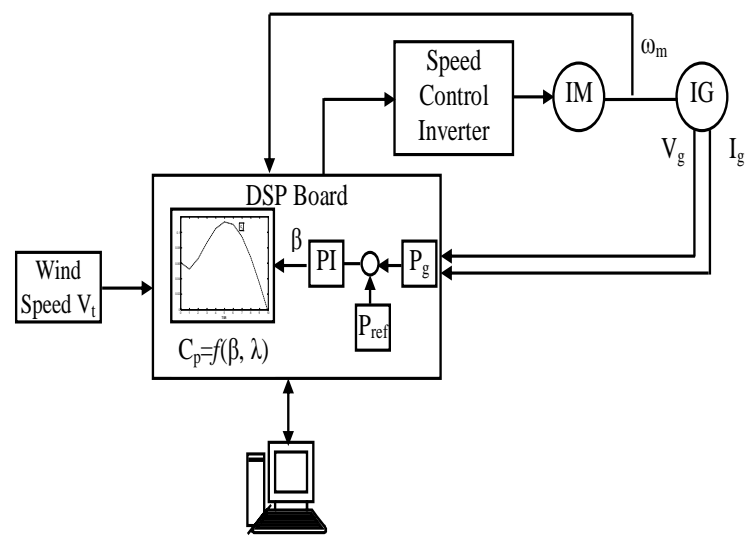

Fig. 1 Schematic of the general construction of Wind Turbine Emulator

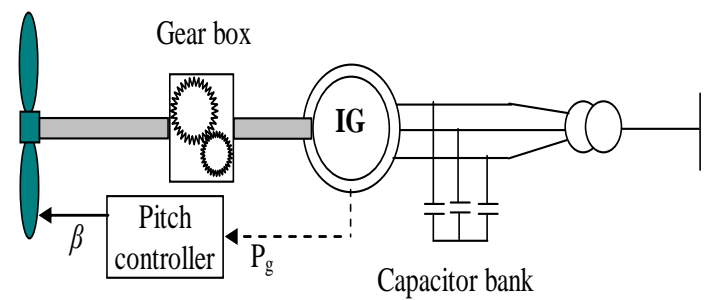

Fig. 2 Schematic diagram of a fixed speed-variable pitch WECS

\section{MATHEMATICAL MODELING OF WIND TURBINES CHARACTERISTICS}

Wind energy is transformed into mechanical energy by a wind turbine that has several blades. A typical horizontal wind turbine with several blades coupled with a gear box to capture and transfer energy to the generator, is shown in Fig. 2. Some 
Tamer A. kawady, MIEEE and Naema Mansour, "A Real Time Emulator Of Variable Pitch Wind Turbines ..."

turbines include a blade pitch angle control for controlling the amount of power to be transformed. According to the blade element theory, the average power and torque developed by a wind turbine are functions of the wind speed $(\mathrm{Vt})$, the rotational speed of the shaft $(\omega \mathrm{m})$, the tip-speed ratio $(\lambda)$, pitch angle $(\beta)$ as given by equations (1) and (2).

$$
\begin{aligned}
& P_{T}=\frac{1}{2} \pi \rho V_{T}^{3} R^{2} C_{p}(\lambda, \beta) \\
& T_{T}=\frac{1}{2} \pi \rho V_{T}^{2} R^{3} C_{T}(\lambda, \beta)
\end{aligned}
$$

Where:

$\mathrm{R}$ : is the radius of the wind turbine.

$\rho:$ is the air density $(1.185 \mathrm{~kg} / \mathrm{m} 2)$.

$\mathrm{CT}:$ is the torque coefficient of the wind turbine.

$\mathrm{Cp}$ : is a power coefficient representing the fraction of power extracted from the aerodynamic power.

The coefficient of performance $\mathrm{Cp}$ is not constant. It varies with the wind speed, the rotational speed of the turbine and turbine blade parameters such as angle of attack and pitch angle. Thus, $\mathrm{Cp}$ is considered a function of tip speed ratio, $\lambda$, and blade pitch angle, $\beta$ (deg). Numerical approximations have been developed to calculate $\mathrm{Cp}$ for given values of $\lambda$ and $\beta$ [11-16]. For the considered $12.7 \mathrm{~kW}$ wind turbine, in particular, the formalization for computing the corresponding $\mathrm{Cp}$ value as a function of $\lambda$ and $\beta$ as,

$$
\begin{aligned}
& C_{p}=.35\left(\frac{100}{\lambda}-.04 \beta^{2}-10\right) e^{-\frac{10}{\lambda}} \\
& C_{T}=\frac{C_{P}}{\lambda}
\end{aligned}
$$

Where

$$
\lambda=\frac{\omega_{t} R}{V_{t}}
$$

The power coefficient Cp (also called the "Bezt factor") has a maximum achievable value of 16/27 (.59) according to the blade element theory. In practice, wind turbines have achieved power capture efficiencies of around 0.4 . The CP- $\lambda$ curves for different values of $\beta$ for wind turbine are shown in Fig. 3 as a function of its Tip Speed Ratio (TSR). Accordingly the corresponding generated wind power as a function of the time varying wind speed for the selected $12.7 \mathrm{~kW}$ real wind turbine was computed as shown in Fig. 4. These characteristics played the basic role for acquiring the aimed torquespeed control of the utilized prime mover according to the given parameters given in Table 1 [6].

Then, the aforementioned equations from (1) to (5) can be compromised with the given parameters of the selected wind turbine to describe the schematic of controlling the computed torque developed by the turbine for a given wind speed as described in Fig. 5.

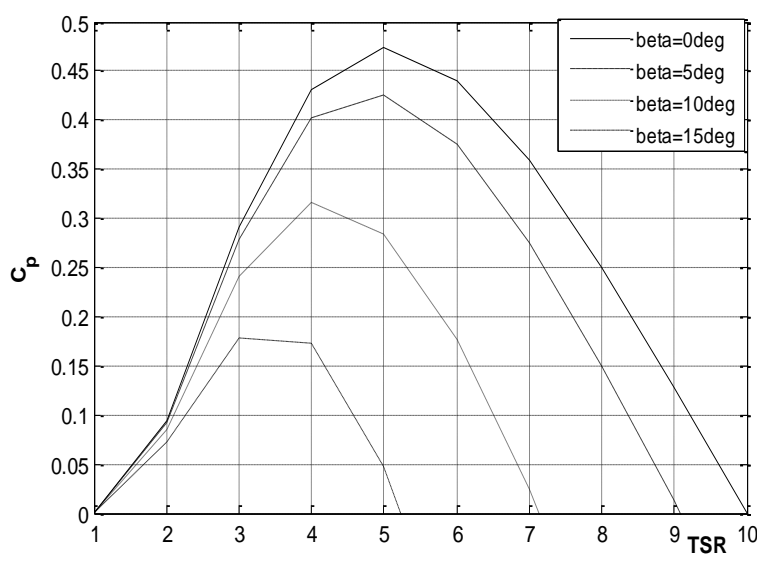

Fig. 3 Cp- $\lambda$ characteristics with adjusted values of $\beta$ for $12.7 \mathrm{~kW}$ wind turbine.

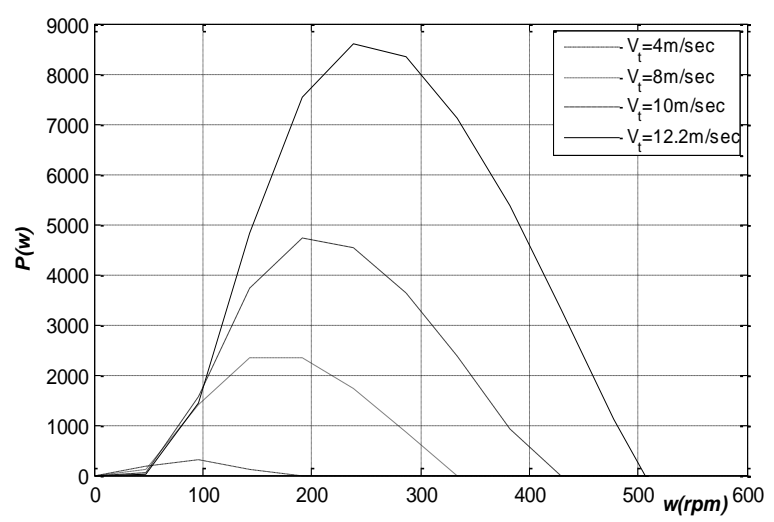

Fig. 4 power speed curves at different wind speed (Characteristics of $12.7 \mathrm{~kW}$ wind turbine).

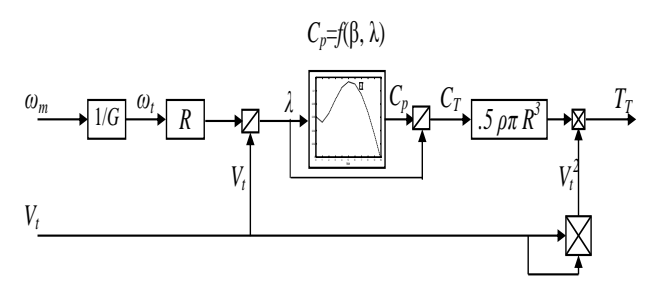

Fig. 5 Block diagram of rotor blade characteristics computational mechanism.

Table 1, Parameters of the utilized $12.7 \mathrm{~kW}$ wind turbine.

\begin{tabular}{|l|l|l|}
\hline Symbol & Quantity (Unit) & Value \\
\hline$R$ & Rotor radius (m) & 2.325 \\
\hline$J$ & Inertia(kg.cm $\left.{ }^{2}\right)$ & 400 \\
\hline$P_{W}$ & Rated power (kW) & 12.7 \\
\hline$\omega_{W}$ & Rated rotating speed (rpm) & 300 \\
\hline$V_{W}$ & Rated wind speed (m/s) & 12.2 \\
\hline$\omega_{M}$ & Maximum rotating speed (rpm) & 500 \\
\hline$V_{S}$ & Startup wind speed (m/s) & 3 \\
\hline$V_{I N}$ & Cut in wind speed (m/s) & 3 \\
\hline$V_{\text {OFF }}$ & Cut off wind speed (m/s) & 20 \\
\hline$T_{S}$ & Startup torque & $12.5 \mathrm{Nm} @ 3 \mathrm{~m} / \mathrm{s}$ \\
\hline
\end{tabular}




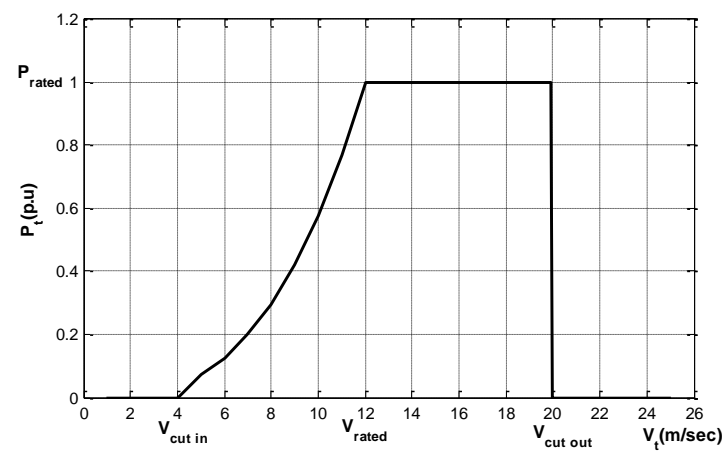

Fig. 6 Wind turbine output power curve for fixed speed-variable pitch control.

\section{PITCH CONTROL MECHANISM}

The main purpose of using pitch controller with wind turbines is to maintain an optimum profile of the generated power with the continuous variation of wind speed. As described in Fig. 6, the primary control objective is to ensure that the mechanical loads on the turbine structure are maintained within its withstand capability limit [9-14]. This means that the pitch control is primarily used to limit the aerodynamic power above rated wind $(\mathrm{Vr})$ speed in order to keep the turbine shaft torque within its design limits. As described from the aforementioned figure, a constant output power is maintained above the rated wind speed condition. Using equation (3), the pitch angle needed to limit the power extracted from the wind to the nominal power of the wind turbine is calculated for each wind speed, whereas a zero pitch angle is maintained for other wind speed below the nominal one [14].

The given block diagram in Fig. 7 was utilized to perform this control action [13]. The reference power is the nominal power output of the wind turbine at rated wind speeds $(\mathrm{Pt})$. Upon the difference of the generated power by the induction generator $(\mathrm{Pg})$ and the reference power, the corresponding error signal is computed. If the power from the wind turbine is less than the nominal power, the error will be a negative value and the pitch controller in this case is designed to set the blade pitch angle to zero. When the captured power by wind turbine is greater than the nominal power, the error will be a positive value and the blade pitch angle is calculated by feeding the error signal to a Proportional Integral (PI) controller. PI control improves the response of system through the values for KP (Proportional gain) and $\mathrm{Ki}$ (Integral gain). KP reduces the rise time of the response and steady state error, however $\mathrm{Ki}$ has the effect of eliminating the steady state error.

\section{DEVELOPED WTE HARDWARE}

The WTE was constructed based on the energy conversion system shown in Fig. 8. The laboratory system was realized by replacing the real wind (with its time varying profile), the gearbox and the mechanical turbine with a7.5 $\mathrm{kW}$ induction motor controlled with a dedicated IGBT based inverter. The mathematical model of the wind turbine upon the given equations (1) to (5) was implemented on the DSP board sub-system to calculate in an on-line mode the reference power. The reference power is then utilized by the PI controller to provide the control signals driving the motor inverter.

The structure of the implemented hardware consists of the following two sub-systems:

$>$ The electro-mechanical system consisting of two coupled $7.5 \mathrm{~kW}$ induction machines as described in Fig. 9 (a).

$>$ Speed sensor constructed with an opto-reflector chip (QRB 1114) as described in Fig. 9 (b).

$>$ Basic control panel consisting of $7.5 \mathrm{~kW}$ IGBTbased inverter, excitation capacitors of the induction generator and switches as described in Fig. 9 (c).

$>$ DSP (DS1003) sub-system from DSPACEGermany [15], [16] including the basic real time firmware emulating the selected $12.7 \mathrm{~kW}$ wind turbine as described in Fig. 9 (d).

$>$ Host PC including the DSP sub-system and its relevant packages for programming, debugging and tracing purposes.

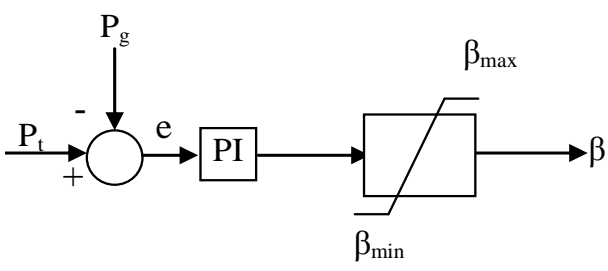

Fig. 7 Pitch angle control system.

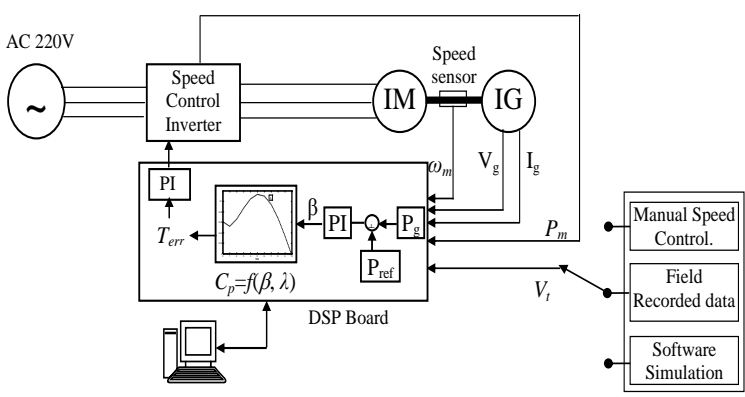

Fig. 8 Constructed WTE hardware setup

The WTE software is implemented based DSP board (DS1003) representing the main core of the emulating action. Firmware Implementation of WTE was preceded by arranging the main DSP sub-system consisting of the multi-input/output (I/O) board DS2201 interfaced with the DSP board DS1003 via a Peripheral High Speed 32-bit bus (PHS-bus) [15, 16]. DS1003 is based on the TMS320C40 float-point $\mathrm{CPU}$ and it is directly used for executing the main program as shown in Fig. 10. The DS2201 board is based on the TMS320B14 fixed-point CPU and it is used to facilitate the interfacing with the real system 
through 20 simultaneous analog input channels, 8 analog output channels, and 16-bit general-purpose digital I/O port. For realizing an optimum enquiring of current and voltage signals, modern "hall effect" CTs and VTs were employed. These transducers are dedicated voltage (current) sensors working for a wide range of electrical signals (including AC \& DC quantities) and generating signals proportional to them. Its operation is based on producing a voltage difference (the Hall voltage) across an electrical conductor, transverse to an electric current in the conductor and a magnetic field perpendicular to the current. The current transducer used in is LEM LA 25-NP, whereas the corresponding voltage transducers were with the LEM VA-25-P.

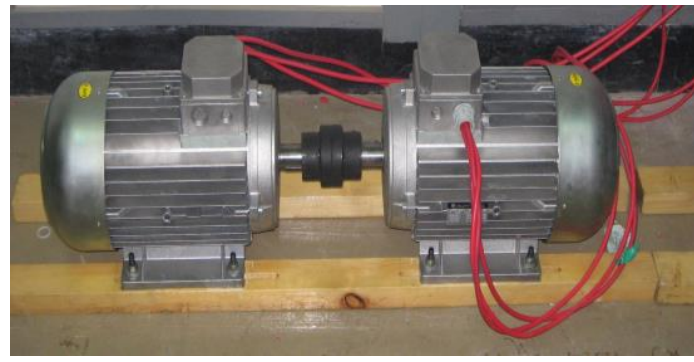

Fig.9.a Induction motor-generator set
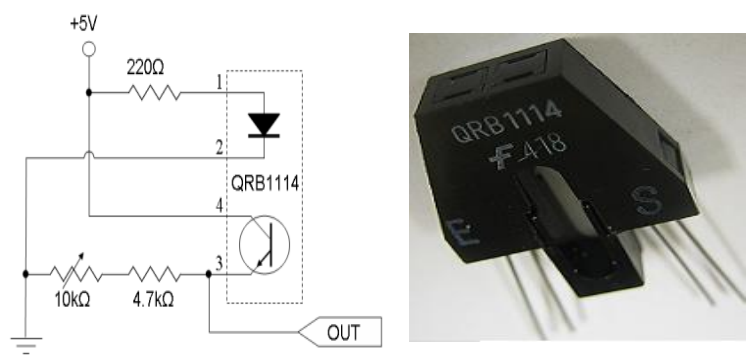

Fig. 9.b Speed sensor

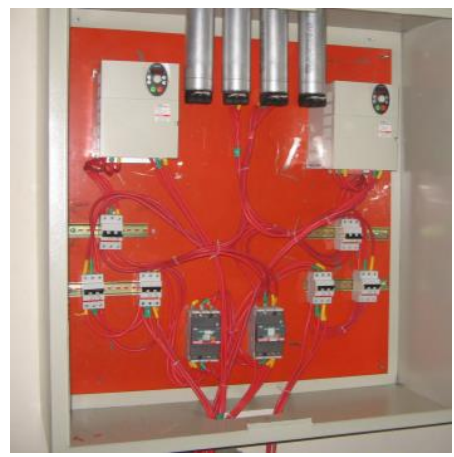

Fig.9.c Main control panel

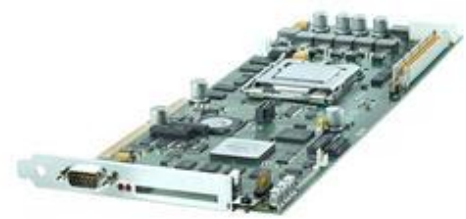

Fig.9.d DSP-subsystem

Fig. 9 Constructed hardware sub-systems for the developed WTE
The scaling circuit is used to adjust the value of the input signals to the ADCs. Changing the gain is helpful to adjust the voltage at the ADC analog input pin to a value that produces maximum resolution. ADC resolution is defined as the minimum value of analog input that can set the lowest significant bit of the digital output by one. Low pass filtering is an essential part of any digital system since it is able to minimize the possibility of occurrence of aliasing. Aliasing is defined as a downward frequency translation which occurs whenever the sampling frequency is less than twice the frequency component to be sampled. Aliasing has very serious effects because the frequency characteristics of the continuous signal and its sampled sequence are no longer linearly related. In order to minimize the aliasing effect, a low pass filter is employed before sampling to reject all those components which have frequencies higher than the half of the sampling frequency of the relay which is selected as $1600 \mathrm{~Hz}$ (Nyquist criteria).

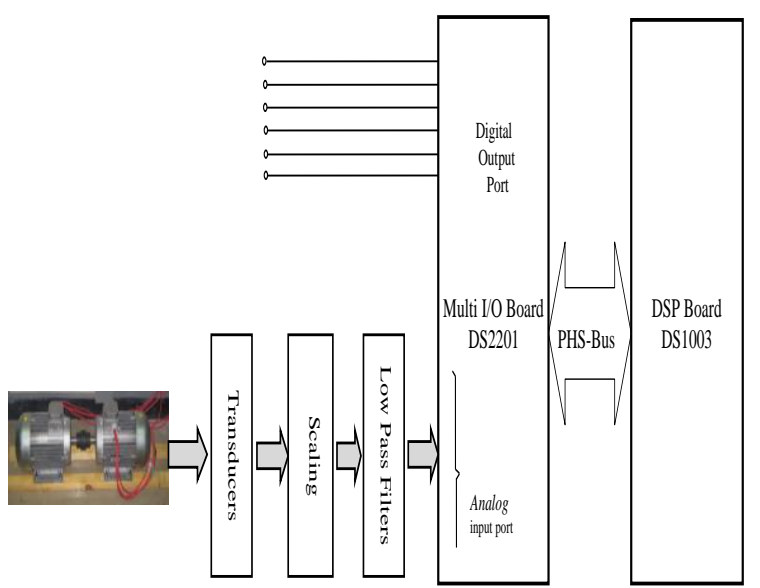

Fig. 10 Construction of the DSP sub-system (DS1003)

The software implementation of WTE is constructed considering the instruction of the DS1003 software environment. In which, the static characteristics of the wind turbine was tabled and stored. The on-line operation of the control mechanism was initiated by measuring the rotational speed $\omega \mathrm{m}$ indicated as the turbine speed $\omega \mathrm{T}$. Then the tip speed ratio $(\lambda)$ is computed. The parameters $\mathrm{CP}$, and CT, needed for the aerodynamic power and torque calculation, can be directly obtained from equations (3) and (4). Then the turbine torque is calculated, and the motor torque is measured to provide a torque error Terr which fed to PI controller. This command will be passed to the speed controlled inverter to drive the motor. A real-time WTE is capable of reproducing the static torque that would be produced by the modeled wind turbine under specific wind conditions. 


\section{EXPERIMENTAL SIMULATOR RESULTS}

Different testing conditions were tested with the constructed WTE including the variation of wind speed. The pitch controller response behind the rated wind speed is also investigated and recorded. Different measurements were recorded including voltages, currents and the pitch angle variations. First, the real-time responses of WTE during wind speed variation from 8 to $10 \mathrm{~m} / \mathrm{sec}$. and from 10 to 8 $\mathrm{m} / \mathrm{sec}$. were recorded as in Fig. 11 and 12 respectively. It can be noticed that the motor torque $(\mathrm{Tm})$ tracked the reference torque $(\mathrm{Tt})$ within $5 \mathrm{sec}$. As remarked from this testing condition, the wind speed variation from 8 to $10 \mathrm{~m} / \mathrm{sec}$. was below the rated wind speed. Then, the pitch controller is still inactive revealing a zero pitch angle during this condition. Similar responses were recorded for the variation of the wind speed (below rated wind speed) between 10 and $12 \mathrm{~m} / \mathrm{sec}$. as recorded in Fig. 13 and 14. This was similarly achieved in $5 \mathrm{sec}$., where the pitch controller was still inactive revealing a zero pitch angle. On the other hand, the utilized pitch controller was activated, if the wind speed exceeded the rated speed of $12 \mathrm{~m} / \mathrm{sec}$. As remarked in Fig. 15 and 16 the pitch angle controller was activated for a step variation of wind speed from 8 to $15 \mathrm{~m} / \mathrm{sec}$. and from 10 to $15 \mathrm{~m} / \mathrm{sec}$. respectively. Then, the resulted wind turbine torque was restored to its nominal value as shown in the aforementioned figures.
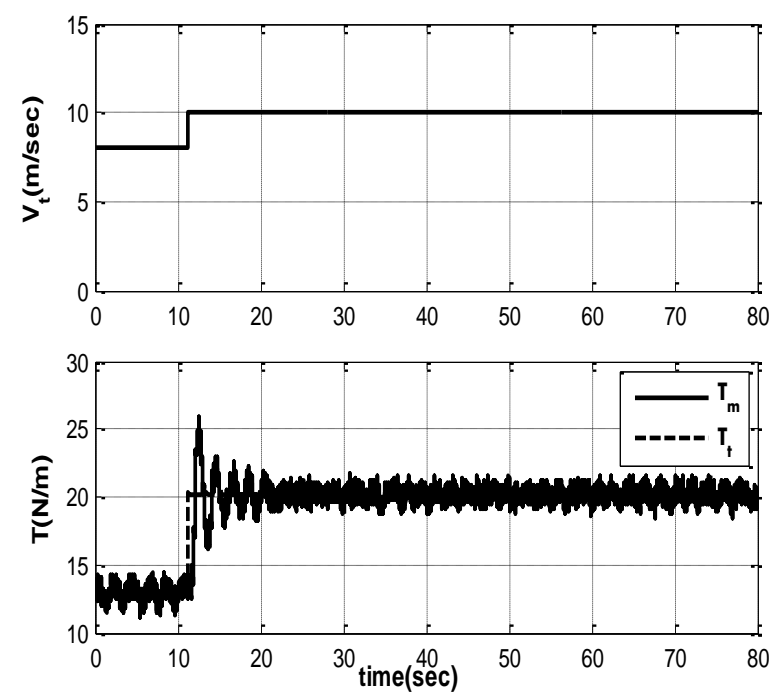

Fig. 11 Simulator response for step change in wind speed from 8 to $10 \mathrm{~m} / \mathrm{sec}$.
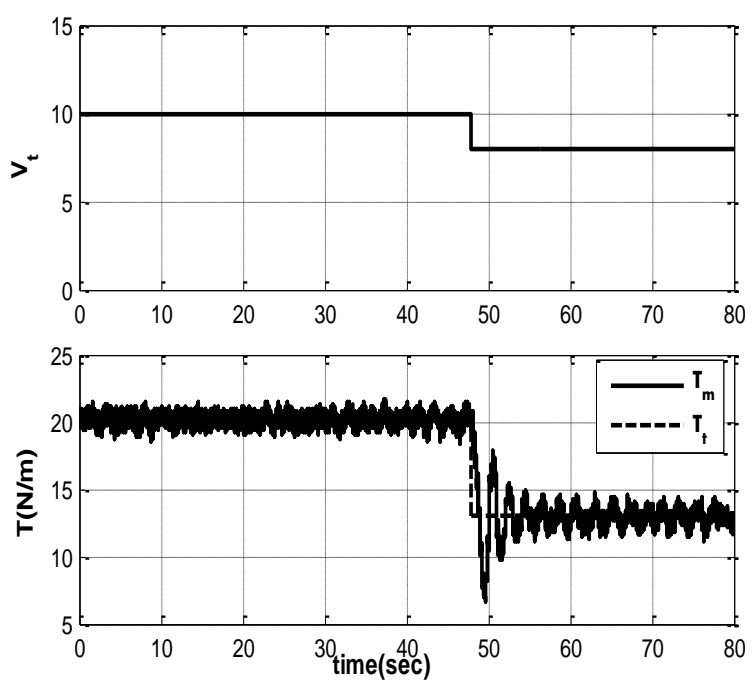

Fig. 12 Simulator response for step change in wind speed from 10 to $8 \mathrm{~m} / \mathrm{sec}$.

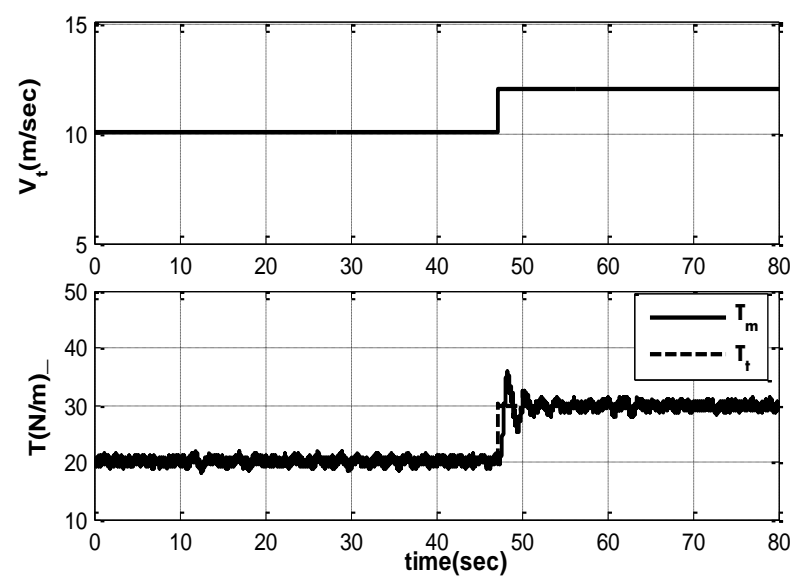

Fig. 13 Simulator response for step change in wind speed from 10 to $12 \mathrm{~m} / \mathrm{sec}$.
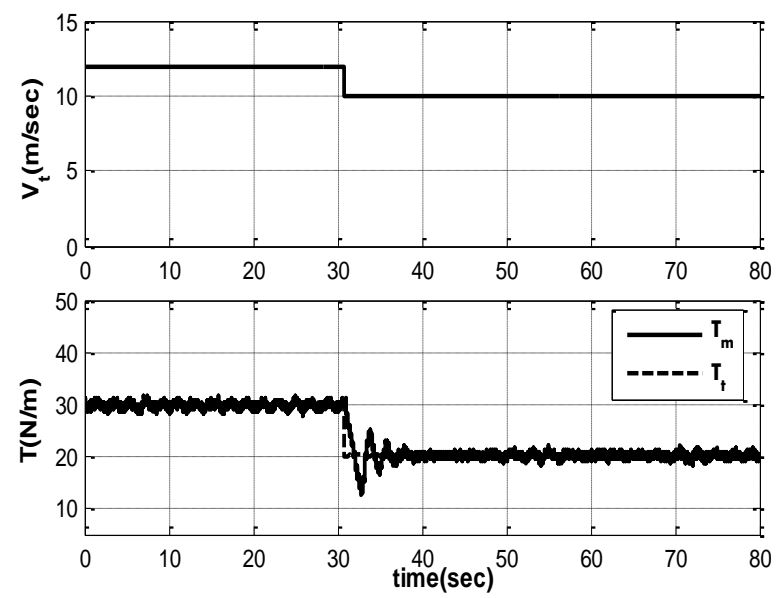

Fig. 14 Simulator response for step change in wind speed from 12 to $10 \mathrm{~m} / \mathrm{sec}$. 

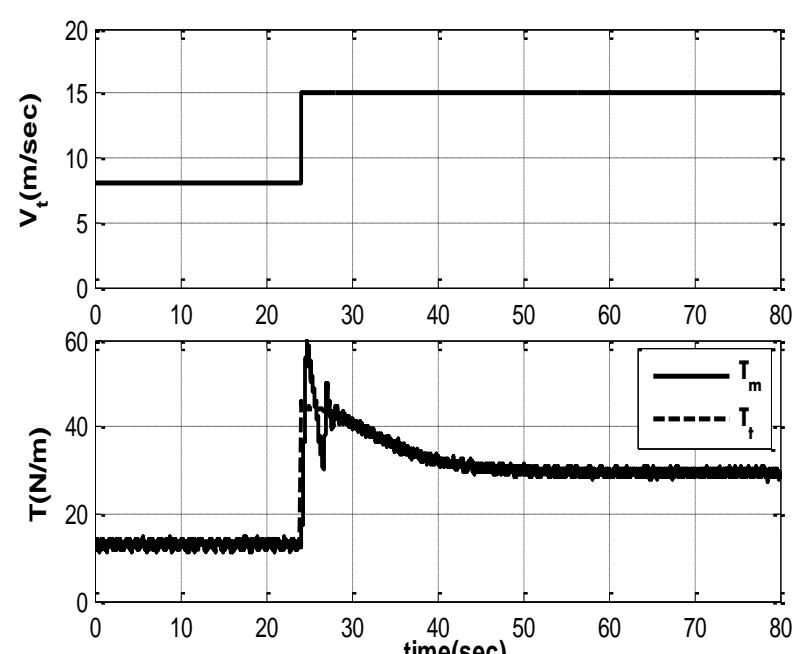

Fig. 15 Simulator response for step change in wind speed from 8 to $15 \mathrm{~m} / \mathrm{sec}$.
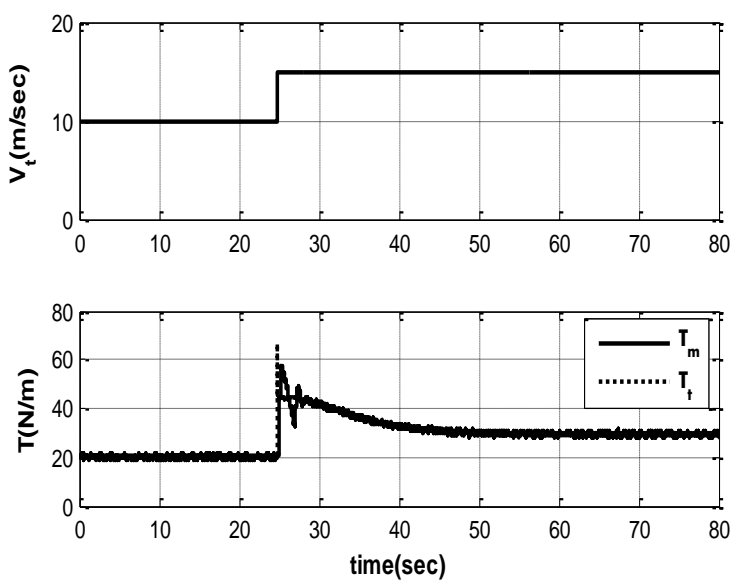

Fig. 16 Simulator response for step change in wind speed from 10 to $15 \mathrm{~m} / \mathrm{sec}$.
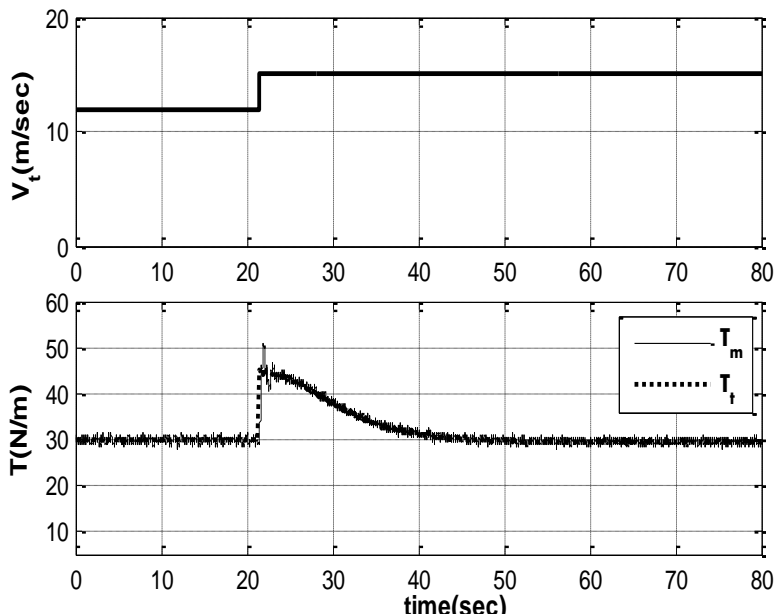

Fig. 17 Simulator response for step change in wind speed from 12 to $15 \mathrm{~m} / \mathrm{sec}$.
Similarly, the pitch controller restored its nominal torque when the wind speed was changed from its rated value 12 to $15 \mathrm{~m} / \mathrm{sec}$. as illustrated in Fig. 17 .

The presented results highlighted the efficacy of developed WTE for emulating the dynamic behavior of the wind energy conversion systems. The role of the pitch control mechanism for optimizing the resulting turbine torque was verified experimentally.

\section{CONCLUSIONS}

In this paper the motor- generator set, DSP, and inverter-based speed controller were used to experimentally simulate fixed speed-variable pitch wind turbine behavior. Two induction motors with $7.5 \mathrm{~kW}$ rated were used to simulate the $12.7 \mathrm{~kW}$ wind turbine with $12 \mathrm{~m} / \mathrm{sec}$ rated wind speed. The dynamic performance of the selected $12.7 \mathrm{~kW}$ wind turbine under wind speed variations below the rated wind are carried out experimentally and the related powerspeed curves of the wind turbine were realized. Also, the pitch controller response of the aforementioned wind turbine during wind speed variation behind the rated wind speed were realized and recorded. This developed WTE with simulated pitch control represent an ideal candidate for performing research as well as educational purposes for wind energy conversion system applications.

\section{REFERENCES}

[1] "Stability Augmentation of a Grid-connected Wind Farm", S.M. Muyeen • Junji Tamura • Toshiaki Murata. 2009 Springer-Verlag London Limited.

[2] Mohammad Monfareda, Hossein Madadi Kojabadib, Hasan Rastegara, "Static and dynamic wind turbine simulator using a converter controlled dc motor". Renewable Energy, Volume 33, Issue 5, May 2008, pp. 906-913, Elsevier, 2008.

[3] Weiwei LI, Dianguo XU, Wei ZHANG, Hongfei MA, " Research on Wind Turbine Emulation based on DC Motor". IEEE Industrial Electronics and Applications Conference, 2007, 23-25 May, 2007, pp.25892593, 2007.

[4] P.E. Battaiotto, R.J. Mantz and P.F. Puleston, "A Wind Turbine Emulator Based On A Dual Dsp Processor System" Control Eng. Practice, Vol. 4, No. 9, 1996, pp. 1261-1266, 1996 Elsevier Science Ltd.

[5] Seung-Ho Song, Byoung-Chang Jeong, JeongHun Oh Gin Venkataramanan Hye-In Lee, Jeong-Jae Kim, "Emulation of Output Characteristics of Rotor Blades Using a Hardware-In-Loop Wind Turbine Simulator", Applied Power Electronics Conference and Exposition, 2005. APEC 2005. Twentieth Annual IEEE Meeting, 6-10 Mars 2005, pp. 1791-1796, IEEE, 2005. 
Tamer A. kawady, MIEEE and Naema Mansour, "A Real Time Emulator Of Variable Pitch Wind Turbines ..."

[6] Yaoqin Jia, Zhaoan Wang, Senior Member, IEEE, "Experimental Study of Control Strategy for Wind Generation System", Power Electronics Specialists Conference, PESC 2007, IEEE, 17-21 June 2007, pp. 1202-1207., 2007.

[7] Bunlung Neammanee*1, Somporn Sirisumrannukul* and Somchai Chatratana, "Development of a Wind Turbine Simulator for Wind Generator Testing" . Neammanee et al. / International Energy Journal, 2007, No. 8, pp. 21-28.

[8] L. Chang, R. Doraiswami, T. Boutot and H. Kojabadi, "Development of a Wind Turbine Simulator for Wind Energy Conversion Systems". Electrical and Computer Engineering, 2000 Canadian Conference on, 710 Mars 2000, IEEE, pp. 550-554, 2000.

[9] Oei-Luen Chen, Member, IEEE, and Yuan-Yih Hsu, Senior Member, IEEE, "Controller Design for an Induction Generator Driven by a Variable-Speed Wind Turbine". IEEE TRANSACTIONS ON ENERGY CONVERSION,, 2006, Vol., No. 3, Sept. 2006.

[10] Novak, P., Ekelund, T., Jovik, I., and Schmidtbauer. "Madding and Control of Variable-Speed Wind-Turbine Drive-System Dynamics", Control Systems Magazine, IEEE, Vol. 15, Issue 4, 1995, pp. 28-38.

[11] Zinger.D.S.. Mu1jadi.E.. and M1ller.A.. "A Simple Control Scheme for Variable Speed Wind Turbines", Proceedings of the Annual Meetings of the IEEE Industrial Applications Society, Oct. 1996, San Diego. LA., USA, 1996.

[12] P. M. Anderson and A. Bose, "Stability simulation of wind turbine systems," IEEE Trans. on Power Apparatus and Systems, vol. 102, pp. 3791-3795, Dec. 1983.

[13] J.G. Slootweg, S.W.H. De Haan, " General model for representing variable speed wind turbines in power system dynamics simulation", IEEE Trans. on Power Systems, Vol.18, No. 1, 2003, pp.144 - 151 .

[14] E. Muljadi, C. P. Butterfield, "Pitch Controlled Variable speed wind turbine generation", IEEE Trans. on Industry Applications, Vol.37, Issue 1, Jan-Feb 2001, pp 240-246.

[15] Software Environment for Modular System, DS1003 Board, dSPACE, Germany, 1995.

[16] Multi-I/O Board DS2201, user guide, dSPACE, Germany, 1995

\section{APPENDIX}

Parameters of $12.7 \mathrm{~kW}$ wind turbine

\begin{tabular}{|l|l|}
\hline$P_{w}$ & $12.7 \mathrm{~kW}$ \\
\hline$\omega_{r}$ & $300 \mathrm{rpm}$ \\
\hline$\omega_{m}$ & $500 \mathrm{rpm}$ \\
\hline$V_{t}$ & $12.2 \mathrm{~m} / \mathrm{sec}$ \\
\hline$V_{m}$ & $20 \mathrm{~m} / \mathrm{sec}$ \\
\hline$V_{\text {cut_in }}$ & $4 \mathrm{~m} / \mathrm{sec}$ \\
\hline$R$ & $2.325 \mathrm{~m}$ \\
\hline
\end{tabular}

\section{Acknowledgement}

The authors are expressing their gratitude to the Egyptian "Scientific and Technological Development Fund" (STDF), Egypt, for funding this work. Deep gratitude to the Egyptian New and Renewable Energy Authority (NREA) an all members in ALZaafarana wind farm for their constructive cooperation and support.

\section{Biographies}

Tamer A. Kawady (M'02) was born in Shebin Elkom, Egypt on Sept. 30, 1972. He received his B.Sc. (honors) and M.Sc. degrees in Electrical Engineering, Menoufiya University, Egypt, Ph.D. degree (excellent) from Technical University Darmstadt, Germany in 1995, 1999 and 2005 respectively. Dr. Kawady is currently an associate professor at Menoufiya University, Egypt since June 2010. His interests are in digital protection, Power system simulation using the Electromagnetic Transient Program (EMTP), digital power system protection and wind energy applications.

N. M. Mansour is born in El-shohadaa, Egypt on 1978. She received her B.Sc. \& M.Sc in Electrical Engineering from Menoufiya University, Egypt in 2000 and 2006, respectively. She has been appointed as a research engineer at the same Department for getting the Ph.D. She conducted her M.Sc thesis on the application of the DWT to line protection. 